(C) 2011 IEEE. Personal use of this material is permitted. Permission from IEEE must be obtained for all other uses, in any current or future media, including reprinting/republishing this material for advertising or promotional purposes, creating new collective works, for resale or redistribution to servers or lists, or reuse of any copyrighted component of this work in other works. 


\title{
A Cascaded Brushless Doubly Fed Induction Generator for Wind Energy Applications Based on Direct Power Control
}

\author{
Yongchang Zhang*†, Zhengxi $\mathrm{Li}^{*}$, Jiefeng $\mathrm{Hu}^{\dagger}$, Wei $\mathrm{Xu}^{\dagger}$, Jianguo Zhu ${ }^{\dagger}$ \\ *Inverter Technologies Engineering Research Center of Beijing, North China University of Technology, Beijing, China \\ ${ }^{\dagger}$ Faculty of Engineering and Information Technology, University of Technology Sydney, NSW 2007, Australia \\ Email: yozhang@ieee.org
}

\begin{abstract}
This paper proposes a direct power control (DPC) strategy for cascaded brushless doubly fed induction generator (CBDFIG), which eliminates the slip rings and brushes in conventional DFIG wind turbine systems and features quick dynamic response and excellent steady state performance. Prior methods for controlling CBDFIG are based on vector control (VC), which is complicated and requires much tuning work and machine parameters. Appropriate decoupling and fine PI tuning are mandatory to obtain good performance over the entire operating range. Furthermore, there are few papers regarding the grid synchronization issue of CBDFIG. This paper firstly analyzes the influence of each voltage vector on active/reactive powers and then proposes a unified switching table for both grid-connected operation and grid synchronization process. The effectiveness of the developed DPC method for CBDFIG is confirmed by the presented simulation results.
\end{abstract}

\section{INTRODUCTION}

Nowadays, vector controlled (VC) doubly fed induction generator (DFIG) based wind energy conversion system (WECS) has become the most common configuration, due to its merits of decoupled active/reactive power control, low converter VA rating and reduced power loss compared to other solutions equipped with fully rated converter [1], [2].

However, this very popular configuration has some inherent problems. On one hand, the use of brushes and slip rings creates a constant need for frequent inspections and maintenance of the generator [3], hence reduces the system reliability and increases the cost. On the other hand, conventional design of DFIG control system is based on rotor current vector control (VC) with dq decoupling, which requires rotary transformation and accurate machine parameters. The system performance will deteriorate when the actual machine parameters differ from the values used in the control system. The multiple control loops in $\mathrm{VC}$ require much tuning effort to ensure the system stability [4], [5].

To tackle the problems above and maintain the advantages of conventional DFIG system, this paper proposes an alternative configuration for WECS. Conventional DFIG is replaced by a cascaded brushless doubly fed generator (CBDFIG) to eliminate the brushes and slip rings, hence improves the system robustness and reliability. VC will be replaced by direct power control (DPC) scheme to achieve better control performance in terms of lower tuning effort and quicker dynamic response.
The CBDFIG can be easily constructed using two doubly fed induction machines, as shown in Fig. 1. The stator of power machine is directly connected to the main grid, while its rotor energy is transferred by using a second fractional control machine, which is directly coupled to the main generator (power machine) through the back-to-back connection of rotor circuit. The shafts of power machine and control machine are mechanically coupled and their rotors are electrically interconnected. As a result, the need for brushes and rotor slip rings is eliminated and better performance in terms of system robustness and reliability can be obtained. The CBDFIG has been proposed to be applied in wind energy applications [3], [6] and hydro-power plants [7].

The CBDFIG inherits almost all merits of conventional DFIG. However, the mathematical model of CBDFIG is more complex. Previous research work on CBDFIG is mainly based on the vector control of stator flux orientation [3], [6], [8]. It is found that although the conventional stator-flux-oriented control of the DFIG can still be applied to CBDFIG, oscillations were observed in both steady state performance and dynamic response [6], [8]. Furthermore, the knowledge of many machine parameters, appropriate decoupling [3], [8] and fine PI gains tuning [6] are necessary to ensure the system performance.

To eliminate the tuning effort in conventional VC and increase the dynamic response, direct torque control (DTC) [9] and direct power control (DPC) [10] were proposed recently . Some methods have been developed to further improve the steady performance of direct control [11], [12]. However, due to the increase complexity in mathematical model of CBDFIG, there are very few papers published regarding the application of DTC/DPC in CBDFIG. Until very recently, the authors introduced DTC to the control CBDFIG [5]. This paper will further investigate DPC in the control of CBDFIG and extend it to both grid-connected operation and grid synchronization process. Simulation results will be presented to verify the effectiveness of the proposed DPC.

\section{Machine Equations of CBDFIG}

The dynamic model of a CBDFIG can be obtained by combining the two wound rotor induction machine models functionally (viewed from the stator side of power machine 


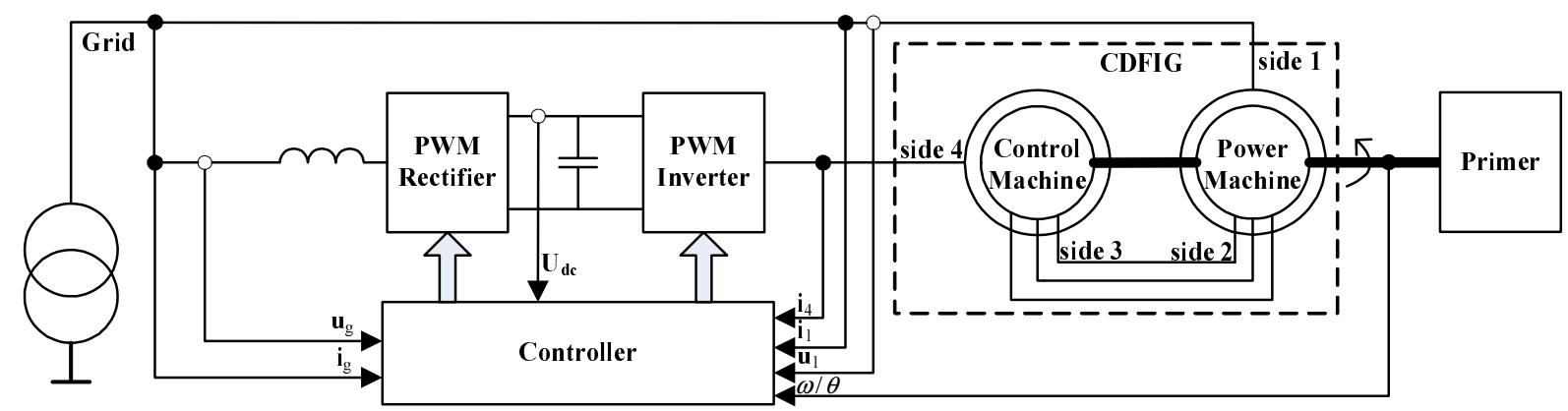

Fig. 1. Configuration of CBDFIG for wind energy applications

(side 1) to stator side of control machine (side 4)), which is expressed in an arbitrary frame (rotating with speed of $\omega_{k}$ ) as [3], [6], [8]:

- Voltage equations:

$$
\begin{aligned}
\boldsymbol{u}_{1}^{k} & =R_{1} \boldsymbol{i}_{1}^{k}+\frac{d \boldsymbol{\psi}_{1}^{k}}{d t}+j \omega_{k} \boldsymbol{\psi}_{1}^{k} \\
0 & =R_{R} \boldsymbol{i}_{2}^{k}+\frac{d \boldsymbol{\psi}_{R}^{k}}{d t}+j\left(\omega_{k}-p_{A} \omega_{m}\right) \boldsymbol{\psi}_{R}^{k} \\
\boldsymbol{u}_{4}^{k} & =R_{4} \boldsymbol{i}_{4}^{k}+\frac{d \boldsymbol{\psi}_{4}^{k}}{d t}+j\left(\omega_{k}-\left(p_{A}+p_{B}\right) \omega_{m}\right) \boldsymbol{\psi}_{4}^{k}
\end{aligned}
$$

- Flux equations:

$$
\begin{aligned}
\boldsymbol{\psi}_{1}^{k} & =L_{1} \boldsymbol{i}_{1}^{k}+L_{1 r} \boldsymbol{i}_{2}^{k} \\
\boldsymbol{\psi}_{R}^{k} & =L_{1 r} \boldsymbol{i}_{1}^{k}+L_{R} \boldsymbol{i}_{2}^{k}-L_{4 r} \boldsymbol{i}_{4}^{k} \\
\boldsymbol{\psi}_{4}^{k} & =-L_{4 r} \boldsymbol{i}_{2}^{k}+L_{4} \boldsymbol{i}_{4}^{k}
\end{aligned}
$$

- Torque equations

$$
T_{e}=\frac{3}{2} \boldsymbol{i}_{2}^{k} \otimes\left(p_{A} L_{1 r} i_{1}^{k}+p_{B} L_{4 r} i_{4}^{k}\right)
$$

Where the subscripts " 1 ", " $R$ " and "4" mean the stator side of power machine (side 1), interconnected rotor side (side 2 and side 3 in Fig. 1) and stator side of control machine (side 4), as shown in Fig. 1. The superscript " $k$ " indicates the rotating speed of $\omega_{k} . \boldsymbol{u}_{1}^{k}, \boldsymbol{i}_{1}^{k}, \boldsymbol{\psi}_{1}^{k}, \boldsymbol{u}_{4}^{k}, \boldsymbol{i}_{4}^{k}, \boldsymbol{\psi}_{4}^{k}, \boldsymbol{i}_{2}^{k}$ and $\boldsymbol{\psi}_{R}^{k}$ are side 1 voltage, side 1 current, side 1 flux, side 4 voltage, side 4 current, side 4 flux, side 2 (and 3) current and combined rotor flux of side 2 and 3 , respectively; $R_{1}, R_{R}, R_{4}, L_{1}, L_{1 r}, L_{4 r}$, $L_{R}$ and $L_{4}$ are the side 1 resistance, combined rotor resistance of side 2 and 3 , side 4 resistance, side 1 inductance, mutual inductance of side 1 , mutual inductance of side 4 , combined rotor inductance of side 2 and 3 , and side 4 inductance; $p_{A}$ and $p_{B}$ are the pole pair numbers of power machine and control machine; $\omega_{r}$ and $\omega_{m}$ are the rotary frame speed and mechanical speed. All variables are viewed from the stator side of power machine [8]. It should be noted that the rotor flux $\psi_{R}^{k}$ is a combination flux of side 2 and side 3 .

Due to the interconnected rotor side, the synchronous mechanical frequency $f_{\text {syn }}$ is obtained as

$$
f_{\text {syn }}=\frac{f_{1}}{p_{A}+p_{B}}
$$

where $f_{1}$ is the side frequency $(\mathrm{Hz})$.

\section{PRINCIPLE OF DPC FOR CBDFIG}

\section{A. Effects of Side 4 Voltage Vectors on Active/Reactive Powers}

From (4) to (6), the currents can be obtained as

$$
\left[\begin{array}{c}
\boldsymbol{i}_{1} \\
\boldsymbol{i}_{r} \\
\boldsymbol{i}_{4}
\end{array}\right]=\frac{1}{\Delta}\left[\begin{array}{ccc}
L_{4} L_{r}-L_{4 r}^{2} & -L_{4} L_{1 r} & -L_{1 r} L_{4 r} \\
-L_{4} L_{1 r} & L_{1} L_{4} & L_{1} L_{4 r} \\
-L_{1 r} L_{4 r} & L_{1} L_{4 r} & L_{1} L_{r}-L_{1 r}^{2}
\end{array}\right]\left[\begin{array}{c}
\boldsymbol{\psi}_{1} \\
\boldsymbol{\psi}_{r} \\
\boldsymbol{\psi}_{4}
\end{array}\right]
$$

where $\Delta=L_{1} L_{4} L_{r}-L_{1} L_{4 r}^{2}-L_{4} L_{1 r}^{2}$.

If side 1 resistance is neglected and the supplied three-phase voltages are sinusoidal and balanced, the relationship between side 1 voltage and flux can be obtained from (1) as

$$
\boldsymbol{u}_{1}=j \omega_{1} \psi_{1}
$$

where $\omega_{1}$ is the frequency of side $1(\mathrm{rad} / \mathrm{s})$.

Considering (9) and the first line in (8), the complex power $S$ in side 1 can be expressed in terms of side 1 flux, side 2 (and 3) flux and side 4 flux as

$$
\begin{aligned}
\boldsymbol{S}= & 1.5\left(\boldsymbol{i}_{1}^{*} \boldsymbol{u}_{1}\right) \\
= & k_{\sigma}\left[j\left(L_{4} L_{r}-L_{4 r}^{2}\right)\left|\boldsymbol{\psi}_{1}\right|^{2}-L_{1 r} L_{4 r}\left(j \boldsymbol{\psi}_{4}^{*} \boldsymbol{\psi}_{1}\right)\right. \\
& \left.-L_{4} L_{1 r}\left(j \boldsymbol{\psi}_{r}^{*} \boldsymbol{\psi}_{1}\right)\right]
\end{aligned}
$$

where $k_{\sigma}=1.5 \omega_{1} / \Delta$. The active power and reactive power can be obtained by decomposing (10a) into real and imaginary components as

$$
\begin{aligned}
P= & k_{\sigma} L_{1 r} \operatorname{Im}\left[\left(L_{4} \boldsymbol{\psi}_{r}^{*}+L_{4 r} \boldsymbol{\psi}_{4}^{*}\right) \boldsymbol{\psi}_{1}\right] \\
Q= & k_{\sigma}\left[\left(L_{4} L_{r}-L_{4 r}^{2}\right)\left|\boldsymbol{\psi}_{1}\right|^{2}-\right. \\
& \left.L_{1 r} \operatorname{Re}\left[\left(L_{4} \boldsymbol{\psi}_{r}^{*}+L_{4 r} \boldsymbol{\psi}_{4}^{*}\right) \boldsymbol{\psi}_{1}\right]\right]
\end{aligned}
$$

From the model of CBDFIG and the power expressions in (11) and (12), it is possible to derive the differentiations of both $P$ and $Q$ analytically, which will help to obtain the influence of side 4 voltage vectors on both active and reactive powers. However, the resulting expressions are very complex and not intuitive, which are not shown in this paper. Instead, numerical calculations will be used to obtain the active/reactive power slopes.

Figs. 2 and 3 graphically illustrate the influence of side 4 voltage vectors on the slopes of active and reactive powers 

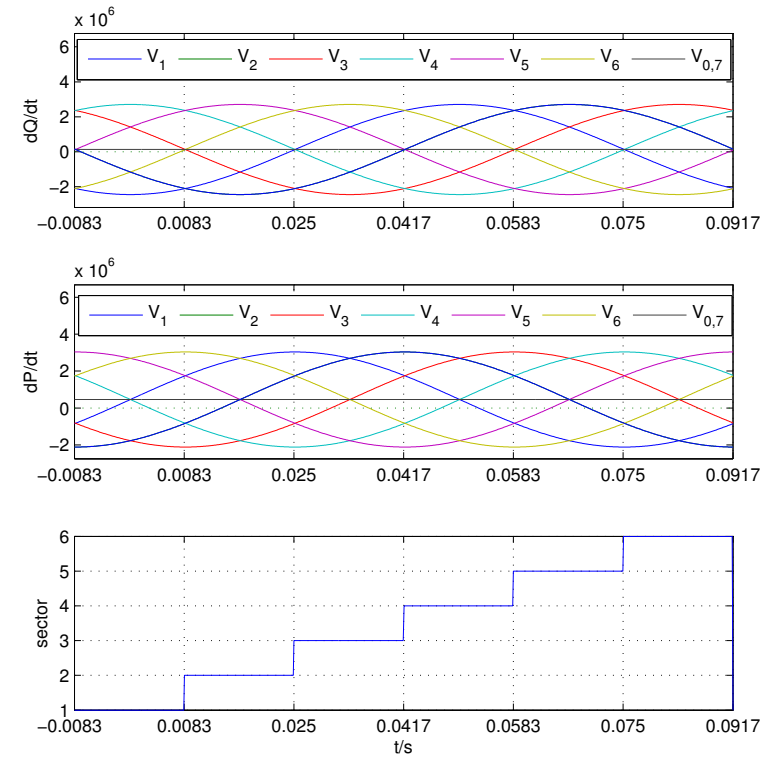

Fig. 2. Active and reactive power slopes versus time for various side 4 voltage vectors at sub-synchronous speed.
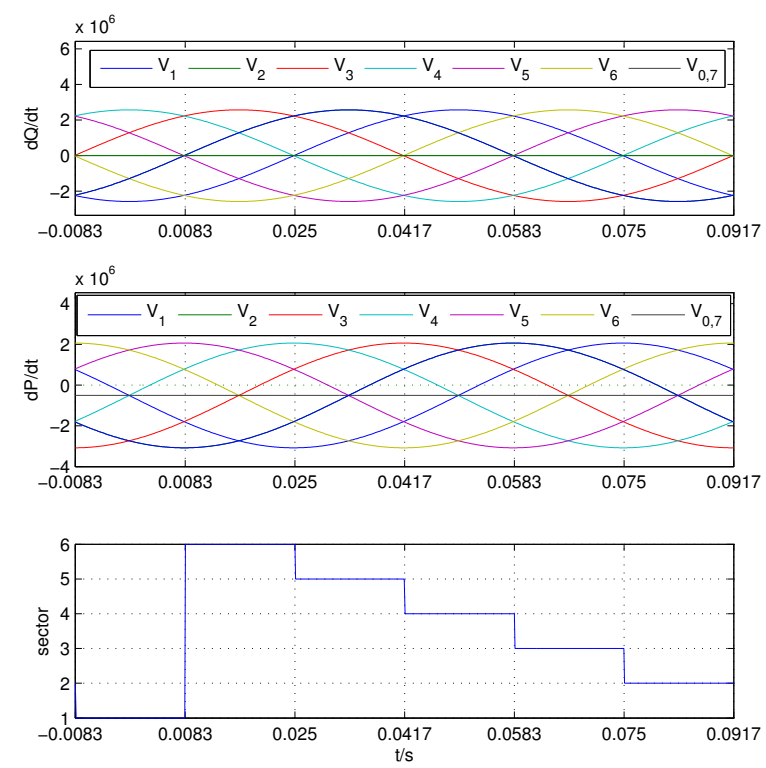

Fig. 3. Active and reactive power slopes versus time for various side 4 voltage vectors at hyper-synchronous speed.

in both sub-synchronous speed and hyper-synchronous speed, respectively. The results are obtained under steady state condition of $20 \mathrm{Nm}$ load. The detailed machine parameters are listed in Section IV. The information of sector, shown at the bottom of Fig. 2, is obtained from the position of stator flux of the control machine (side 4). The sector division for DTC of CBDFIG is shown in Fig. 4, viewed from the control machine (side 4), where sub-synchronous rotor speed is assumed.

\section{B. DPC for Grid Connected Operation}

From Figs. 2 and 3, the switching table for active power and reactive power regulation of CBDFIG can be obtained in Tab.

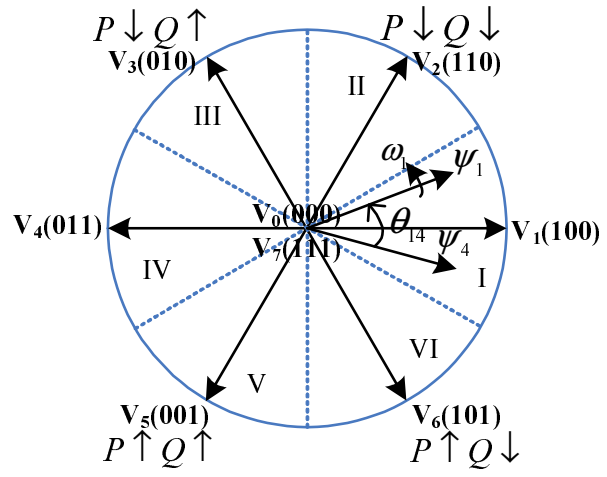

Fig. 4. Sector division for DPC of CBDFIG.

TABLE I

SWITCHING TABLE FOR DPC OF CBDFIG

\begin{tabular}{ccc}
\hline$Q$ & $P$ & vector no. \\
\hline$\uparrow$ & $\uparrow$ & $\mathrm{k}-2$ \\
$\uparrow$ & $\downarrow$ & $\mathrm{k}+2$ \\
$\downarrow$ & $\uparrow$ & $\mathrm{k}-1$ \\
$\downarrow$ & $\downarrow$ & $\mathrm{k}+1$ \\
\hline
\end{tabular}

I, where $k$ is the sector number obtained from the position of $\psi_{4}$. For example, if $\psi_{4}$ is located in the first sector, the desired voltage vector for increasing/decreasing of active and reactive power is illustrated in Fig. 4.

The influence of the null vector on active power is similar to that on torque (shown in [5]), i.e. $\frac{d P}{d t}>0$ for sub-synchronous speed and $\frac{d P}{d t}<0$ for hyper-synchronous speed irrespective of motor or generating mode. On the contrary, the influence of the null vector on reactive power is dependent on both speed and running mode. This can be explained by (12). The amplitude of side 1 flux $\psi_{1}$ can be considered constant due to its stiff connection to the grid (neglecting the resistance voltage drop). The influence of null vector on side 4 flux is very small [5], so the amplitude of $\psi_{4}$ can also be considered constant. As a result, the slope of reactive power $Q$ caused by the null vector can be obtained from (12) as

$$
\frac{d Q}{d t}=k_{\sigma} L_{1 r} L_{4 r}\left|\boldsymbol{\psi}_{4}\right|\left|\boldsymbol{\psi}_{1}\right| \sin \theta_{14} \cdot\left(\omega_{1}-\omega_{4}\right)
$$

where $\theta_{14}$ is the angle $\boldsymbol{\psi}_{1}$ leading $\boldsymbol{\psi}_{4}$ and $\omega_{4}=\left(p_{A}+p_{B}\right) \omega_{m}$ . The influence of $\boldsymbol{\psi}_{R}$ was neglected in (13) due to its small value [5].

From (13) it is easily concluded that $\frac{d Q}{d t}>0$ for subsynchronous speed $\left(\omega_{1}>\omega_{4}\right)$ at motor mode $\left(\theta_{1}>\theta_{4}\right)$ or hyper-synchronous speed $\left(\omega_{1}<\omega_{4}\right)$ at generator mode $\left(\theta_{1}<\theta_{4}\right)$, otherwise $\frac{d Q}{d t}<0$ for sub-synchronous speed at generator mode or hyper-synchronous speed at motor mode. The influences of a null side 4 voltage vector on torque and side 4 flux are summarized in Tab. II. Due to the complicated influences of null vector, it is not used in Tab. I to decrease the implementation complexity.

\section{DTC for Grid Synchronization Operation}

Before connecting to the grid, the terminal of side 1 is open, i.e. $\boldsymbol{i}_{1}=0$. As a result, the machine equations of CBDFIG in 
TABLE II

EFFECTS OF NULL VOLTAGE VECTOR ON ACTIVE AND REACTIVE POWERS

\begin{tabular}{cccc}
\hline mode & $P$ & $Q$ \\
\hline motor & sub & $\uparrow$ & $\uparrow=$ \\
motor & hyper & $\downarrow$ & $\downarrow=$ \\
generator & sub & $\uparrow$ & $\downarrow=$ \\
generator & hyper & $\downarrow$ & $\uparrow=$ \\
\hline
\end{tabular}

(1) to (6) are simplified as

$$
\begin{aligned}
\boldsymbol{u}_{1}^{k} & =\frac{d \boldsymbol{\psi}_{1}^{k}}{d t}+j \omega_{k} \boldsymbol{\psi}_{1}^{k} \\
0 & =R_{R} \boldsymbol{i}_{2}^{k}+\frac{d \boldsymbol{\psi}_{R}^{k}}{d t}+j\left(\omega_{k}-p_{A} \omega_{m}\right) \boldsymbol{\psi}_{R}^{k} \\
\boldsymbol{u}_{4}^{k} & =R_{4} \boldsymbol{i}_{4}^{k}+\frac{d \boldsymbol{\psi}_{4}^{k}}{d t}+j\left(\omega_{k}-\left(p_{A}+p_{B}\right) \omega_{m}\right) \boldsymbol{\psi}_{4}^{k} \\
\boldsymbol{\psi}_{1}^{k} & =L_{1 r} i_{2}^{k} \\
\boldsymbol{\psi}_{R}^{k} & =L_{R} \boldsymbol{i}_{2}^{k}-L_{4 r} \boldsymbol{i}_{4}^{k} \\
\boldsymbol{\psi}_{4}^{k} & =-L_{4 r} \boldsymbol{i}_{2}^{k}+L_{4} \boldsymbol{i}_{4}^{k}
\end{aligned}
$$

To achieve soft and quick grid synchronization, the induced side voltage $\boldsymbol{u}_{1}$ must match the grid voltage $\boldsymbol{u}_{g}$ in terms of amplitude, frequency and phase sequence. This can be achieved by controlling their integrals to be identical, i.e. $\boldsymbol{\psi}_{1}=\boldsymbol{\psi}_{g}$, where $d \boldsymbol{\psi}_{g} / d t=\boldsymbol{u}_{g}$. From (17) to (19), the relationship between $\psi_{4}$ and $\psi_{1}$ can be obtained as [5]

$$
\boldsymbol{\psi}_{4}=\frac{L_{4} L_{R}-L_{4 r}^{2}}{L_{1 r} L_{4 r}} \boldsymbol{\psi}_{1}-\frac{L_{4}}{L_{4 r}} \boldsymbol{\psi}_{R}
$$

where $\psi_{R}$ can be neglected due to its small value. When grid synchronization is achieved, $\boldsymbol{\psi}_{4}$ should satisfy the following equation as

$$
\boldsymbol{\psi}_{4}=\frac{L_{4} L_{R}-L_{4 r}^{2}}{L_{1 r} L_{4 r}} \boldsymbol{\psi}_{g}=\frac{L_{4} L_{R}-L_{4 r}^{2}}{L_{1 r} L_{4 r}} \frac{\boldsymbol{u}_{g}}{\omega_{g}}
$$

where $\omega_{g}$ is the grid frequency ( $\left.\mathrm{rad} / \mathrm{s}\right)$.

There are various ways to control $\psi_{4}$, however, in this paper it is desirable to incorporate the grid synchronization in the principle of DPC, which can work in both grid-connected mode and grid synchronization process. To achieve this aim, a virtual complex power is defined as

$$
\boldsymbol{S}_{v}=k_{\sigma}\left[j\left(L_{4} L_{r}-L_{4 r}^{2}\right)\left|\boldsymbol{\psi}_{g}\right|^{2}-L_{1 r} L_{4 r}\left(j \boldsymbol{\psi}_{4}^{*} \boldsymbol{\psi}_{g}\right)\right]
$$

which is obtained from (10a) by replacing $\psi_{1}$ with grid flux $\boldsymbol{\psi}_{g}$ and neglecting the item containing $\boldsymbol{\psi}_{r}$. There are small difference between $\boldsymbol{\psi}_{g}$ and $\boldsymbol{\psi}_{s}$ in grid-connected mode, so the switching table in Tab. I still works for for the process of grid synchronization, as shown in the simulation results.

The reference value of virtual complex power is $\boldsymbol{S}_{v}^{r e f}=0$, which is obtained by substituting (21) into (22).

\section{Simulation Results}

To confirm the effectiveness of the proposed DPC for CBDFIG, it is simulated in the environment of Matlab/Simulink. The CBDFIG is composed of two identical $8.5 \mathrm{~kW}$ wound
TABLE III

CONTROL AND MACHine PARAMETERs

\begin{tabular}{lcr}
\hline DC-bus voltage [V] & $V_{d c}$ & 560 \\
Rated motor power [kW] & $P_{N}$ & 8.5 \\
Rated motor voltage [V] & $U_{N}$ & 380 \\
Rated (Based) motor frequency [Hz] & $f_{N}$ & 50 \\
Number of motor pairs & $N_{p}$ & 3 \\
Motor stator resistance [ $\Omega]$ & $R_{s}$ & 0.474 \\
Motor rotor resistance [ $\Omega]$ & $R_{r}$ & 0.761 \\
Motor mutual inductance [H] & $L_{m}$ & 0.107 \\
Motor stator inductance [H] & $L_{s}$ & 0.12 \\
Motor rotor inductance [H] & $L_{r}$ & 0.122 \\
\hline
\end{tabular}

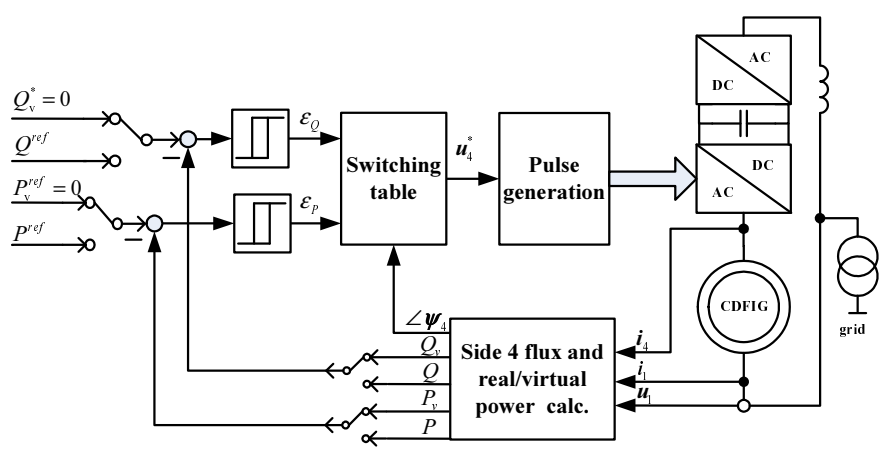

Fig. 5. Control diagram of grid synchronization and grid connected operation for CBDFIG using DTC.

rotor induction machines and the parameters of each $8.5 \mathrm{~kW}$ machine are shown in Tab. III. Fig. 5 illustrates the control diagram of DPC for CBDFIG. The sampling frequency is 20 $\mathrm{kHz}$ and the band width of hysteresis comparator for DPC is zero.The switching between grid-connected operation and grid synchronization process is achieved using a single-pole double-throw switch, as shown in Fig. 5. The grid synchronization process is firstly enabled and when the induced side 1 voltage matches the grid voltage, the side 1 terminal can be connected to the grid. The results for the various stages are shown in the following simulation results.

\section{A. Responses Before Grid Connection}

Firstly, the dc-link voltage is established by controlling the grid side AC-DC converter in Fig. 5. This process in not show in this paper. The side 4 converter (DC-AC converter in Fig. 5) is enabled at $t=0.05 \mathrm{~s}$. The responses of virtual active power, virtual reactive power and side 4 currents during the grid synchronization process are shown in Fig. 6 . The virtual active/reactive powers reach their respective commanding value very quickly. The quick performance is further confirmed in Fig. 7, where the responses of side 1 voltage/flux and grid voltage/flux are shown. It is seen that the side 1 flux matches the grid flux very quickly, only in about 5 milliseconds. Although there is some minor differences between the grid flux and side 1 flux at steady state, this difference is so small that it does not cause any overcurrent in side 4 or any other influences on the grid synchronization process. The soft and fast grid synchronization validates the effectiveness of the grid synchronization technique introduced in Section III-C. 

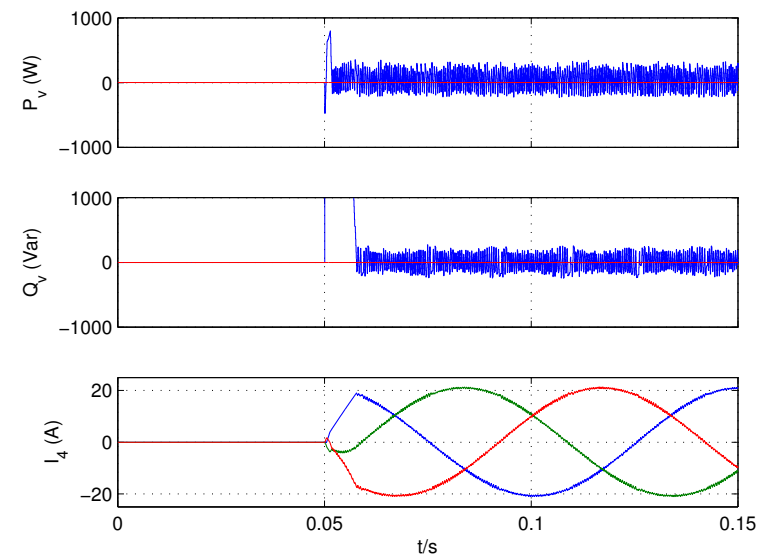

Fig. 6. Responses of side 4 virtual active power, reactive power and side 4 currents during the grid synchronization process
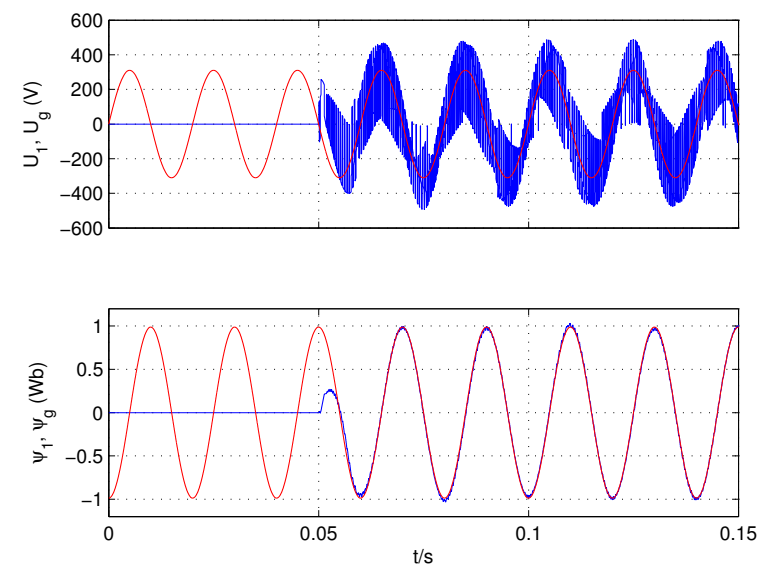

Fig. 7. Responses of side 1 voltage and flux and grid voltage and flux before grid connection

\section{B. Responses During Grid Connection}

Fig. 8 presents the responses of side 1 active/reactive powers, side 1 currents and side 4 currents during the process of grid connection, where the side 1 terminal of CBDFIG is connected to the grid at $\mathrm{t}=0.2 \mathrm{~s}$. The responses of side 1 voltage/flux and grid voltage/flux during grid connection process are shown in Fig. 9. It should be noted that the active/reactive powers shown in Fig. 8 are virtual powers estimated from (22) before $\mathrm{t}=0.2 \mathrm{~s}$ and real powers calculated from (10a) after $\mathrm{t}=0.2$ $\mathrm{s}$. The commanding values of active/reactive powers are zero during this process.

\section{Responses After Grid Connection}

Fig. 10 shows the responses of active power, reactive power, side 1 currents, side 4 currents and side 4 flux for grid connected operation with stepped active power reference at 0.8 pu synchronous speed. The reactive power is kept at zero while there are stepped changes in the active power at $\mathrm{t}=0.3 \mathrm{~s}$ and $\mathrm{t}=0.4 \mathrm{~s}$. It is seen that the active power follows its commanding value closely, showing excellent dynamic performance and tracking ability. The amplitude of the combined rotor flux $\psi_{R}$

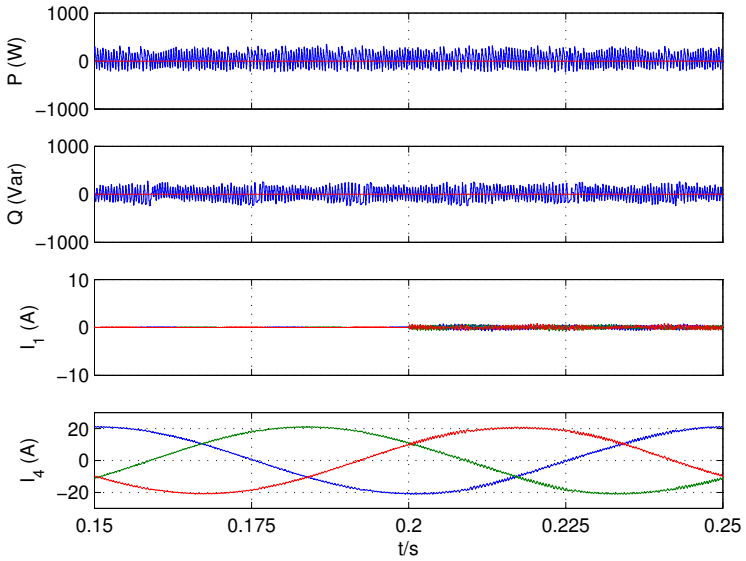

Fig. 8. Responses of side 1 active/reactive powers, side 1 currents and side 4 currents during grid connection
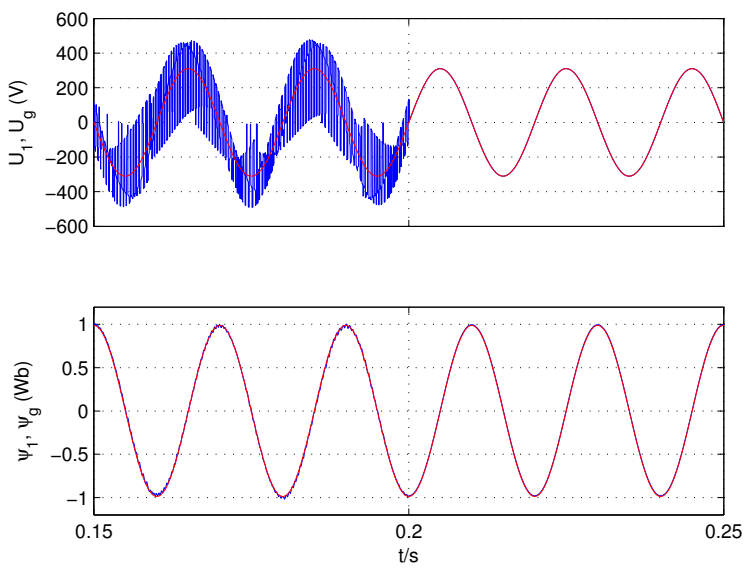

Fig. 9. Responses of side 1 voltage/flux and grid voltage/flux during grid connection
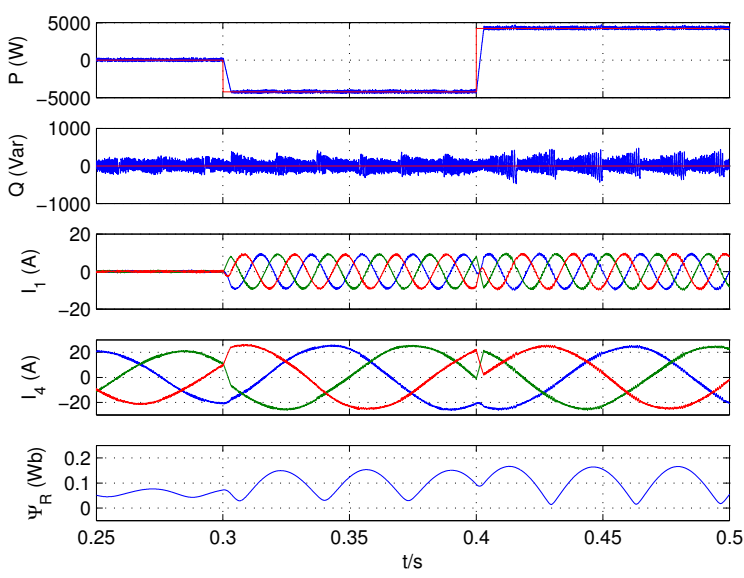

Fig. 10. Responses of active power, reactive power, side 1 currents, side 4 currents and side 4 flux for grid connected operation with stepped active power reference at 0.8 pu synchronous speed

during this process is shown at the bottom of Fig. 10. The small value of $\psi_{R}$ confirmed the feasibility of the controller design in Section III. 

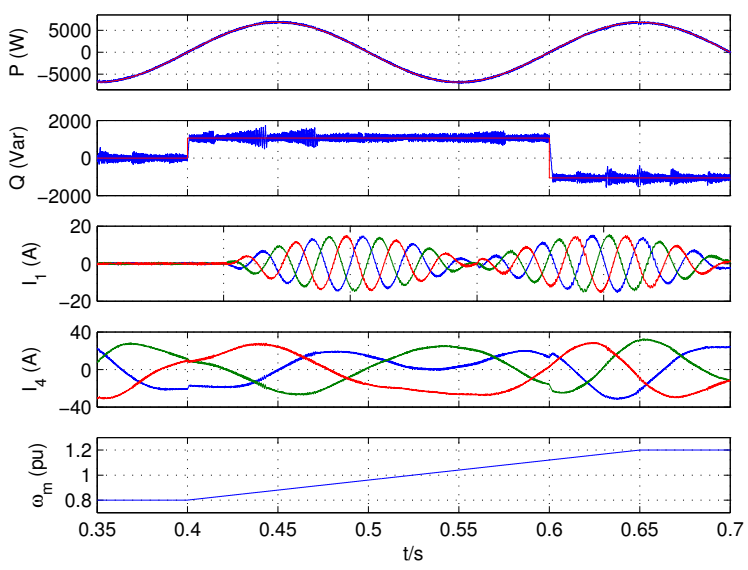

Fig. 11. Responses of active power, reactive power, side 1 currents and side 4 currents for grid connected operation with stepped side 4 flux reference and sinusoidal torque reference under the condition of variable speed
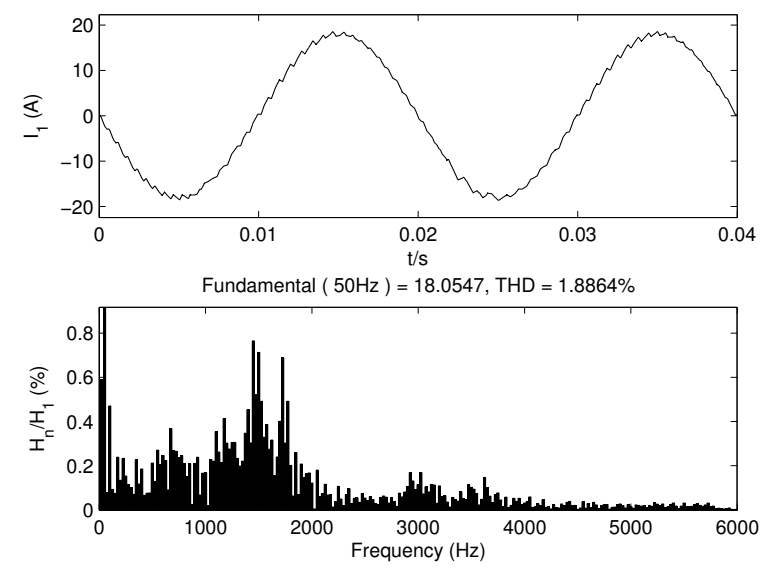

Fig. 12. Harmonic spectrum of side 1 current

The responses of DPC controlled CBDFIG with sinusoidal active power and stepped reactive power under the condition of variable speed are shown in Fig. 11. The generator speed varies from from $0.8 \mathrm{pu}$ to $1.2 \mathrm{pu}$ during the time of $0.4 \mathrm{~s}$ to $0.65 \mathrm{~s}$ and there are stepped changes in the commanding value of reactive power at $t=0.4 \mathrm{~s}$ and $\mathrm{t}=0.6 \mathrm{~s}$. It is seen that during the dynamic process, the active and reactive powers can track their respective commanding value closely, irrespective of the stepped or sinusoidal reference value, showing excellent dynamic performance and tracking ability.

Figs. 12 and 13 present the harmonic spectra of side 1 and side 4 currents at steady state of $P=8.5 \mathrm{~kW}$ and $Q=0$ Var at $0.8 \mathrm{pu}$ synchronous speed. The average switching frequency of DC-AC converter is $1.58 \mathrm{kHz}$. The low THD and sinusoidal shape in both side 1 and side 4 currents validate the good steady state performance of the developed DPC.

\section{CONCLUSION}

This paper proposes an alternative configuration to conventional VC-based DFIG wind turbine system. The DFIG is replaced by CBDFIG to eliminate the brushes and slip
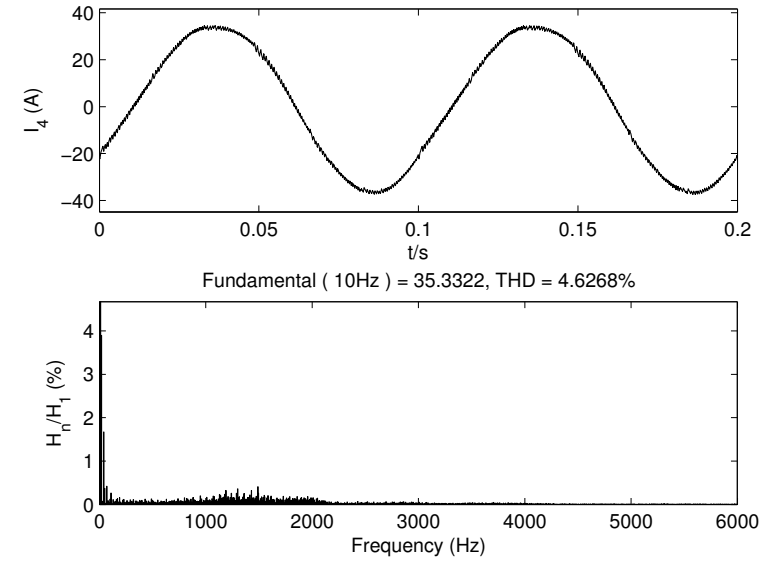

Fig. 13. Harmonic spectrum of side 4 current

rings and VC is replaced by DPC. Despite the increased complexity in the model of CBDFIG, the developed DPC is very simple and can be easily extended to both grid-connected operation and grid synchronization process without changing the switching table. Simulation results prove that excellent dynamic response and steady state performance are achieved by using the developed method in this paper.

\section{REFERENCES}

[1] H. Polinder, F. F. A. van der Pijl, G.-J. de Vilder, and P. J. Tavner, "Comparison of direct-drive and geared generator concepts for wind turbines," IEEE Trans. Energy Convers., vol. 21, no. 3, pp. 725-733, 2006.

[2] Y. Zhang, J. Zhu, and J. Hu, "Model predictive direct torque control for grid synchronization of doubly fed induction generator," in Proc. IEEE Int. Electric Machines and Drives Conf. IEMDC '11, 2011, pp. $775-780$.

[3] K. Protsenko and D. Xu, "Modeling and control of brushless doubly-fed induction generators in wind energy applications," IEEE Trans. Power Electron., vol. 23, no. 3, pp. 1191-1197, 2008.

[4] R. Pena, J. C. Clare, and G. M. Asher, "Doubly fed induction generator using back-to-back pwm converters and its application to variable-speed wind-energy generation," IEE Proceedings -Electric Power Applications, vol. 143, no. 3, pp. 231-241, 1996.

[5] Y. Zhang and J. Zhu, "Direct torque control of cascaded brushless doubly fed induction generator for wind energy applications," in Proc. IEEE Int. Electric Machines and Drives Conf. IEMDC '11, 2011, pp. 751-756.

[6] D. Basic, J. G. Zhu, and G. Boardman, "Transient performance study of a brushless doubly fed twin stator induction generator," IEEE Trans. Energy Convers., vol. 18, no. 3, pp. 400 - 408, sept. 2003.

[7] S. Kato, N. Hoshi, and K. Oguchi, "Small-scale hydropower," IEEE Ind. Appl. Mag., vol. 9, no. 4, pp. 32-38, 2003.

[8] B. Hopfensperger, D. J. Atkinson, and R. A. Lakin, "Stator flux oriented control of a cascaded doubly-fed induction machine," IEE Proceedings -Electric Power Applications, vol. 146, no. 6, pp. 597-605, 1999.

[9] S. Arnalte, J. Burgos, and J. Rodriguez-Amenedo, "Direct torque control of a doubly-fed induction generator for variable speed wind turbines," Electric power components and systems, vol. 30, no. 2, pp. 199-216, 2002.

[10] R. Datta and V. Ranganathan, "Direct power control of grid-connected wound rotor induction machine without rotor position sensors," IEEE Trans. Power Electron., vol. 16, no. 3, pp. 390 -399, may 2001.

[11] Y. Zhang and J. Zhu, "Direct torque control of permanent magnet synchronous motor with reduced torque ripple and commutation frequency," IEEE Trans. Power Electron., vol. 26, no. 1, pp. $235-248,2011$.

[12] Y. Zhang, J. Zhu, W. Xu, and Y. Guo, "A simple method to reduce torque ripple in direct torque-controlled permanent-magnet synchronous motor by using vectors with variable amplitude and angle," IEEE Trans. Ind. Electron., vol. 58, no. 7, pp. 2848-2859, 2011. 